\title{
A case study on occurrence of an unusual structure in the sodium layer over Gadanki, India
}

\author{
Sumanta Sarkhel ${ }^{1,2,3,4^{*}}$, John D Mathews ${ }^{1}$, Shikha Raizada ${ }^{2}$, Ramanathan Sekar ${ }^{5}$, Dibyendu Chakrabarty ${ }^{5}$, \\ Amitava Guharay ${ }^{6}$, Geonhwa Jee ${ }^{3}$, Jeong-Han Kim³, Robert B Kerr², Geetha Ramkumar ${ }^{7}$, Sundararajan Sridharan ${ }^{8}$, \\ Qian Wu ${ }^{9}$, Martin G Mlynczak ${ }^{10}$ and James M Russell II $^{11}$
}

\begin{abstract}
The height-time-concentration map of neutral sodium (Na) atoms measured by a Na lidar during the night of 18 to 19 March 2007 over Gadanki, India (13.5 $\left.\mathrm{N}, 79.2^{\circ} \mathrm{E}\right)$ reveals an unusual structure in the Na layer for around $30 \mathrm{~min}$ in the altitude range of 92 to $98 \mathrm{~km}$ which is similar to the usual ' $C$ ' type structures observed at other locations. In order to understand the physical mechanism behind the generation of this unusual event, an investigation is carried out combining the data from multiple instruments that include the meteor wind radar over Thiruvananthapuram, India $\left(8.5^{\circ} \mathrm{N}, 77^{\circ} \mathrm{E}\right)$ and the SABER instrument onboard the TIMED satellite. The temperature and wind profiles from the data set provided by these instruments allow us to infer the Richardson number which is found to be noticeably less than the canonical threshold of 0.25 above $92 \mathrm{~km}$ over Thiruvananthapuram suggesting the plausible generation of Kelvin-Helmholtz $(\mathrm{KH})$ billows over southwestern part of the Indian subcontinent. Based on the average wind speed and direction over Thiruvananthapuram, it is proposed that the KH-billow structure was modified due to the background wind and was advected with it in nearly 'frozen-in' condition (without significant decay) in the northeastward direction reaching the Na lidar location (Gadanki). This case study, therefore, presents a scenario wherein the initially deformed KH-billow structure survived for a few hours (instead of a few minutes or tens of minutes as reported in earlier works) in an apparently 'frozen-in' condition under favorable background conditions. In this communication, we suggest a hypothesis where this deformed KH-billow structure plays crucial role in creating the abovementioned unusual structure observed in the Na layer over Gadanki.
\end{abstract}

\section{Background}

Mesospheric Na was discovered via measurements of nighttime spectral emissions at the wavelength corresponding to the $\mathrm{NaD}_{2}(589.0 \mathrm{~nm})$ emission resonance line (Slipher 1929). The ablation of meteoroids and interplanetary dust in the mesosphere and lower thermosphere (MLT) (80 to $130 \mathrm{~km}$ ) gives rise to the mesospheric $\mathrm{Na}$ layer. Mathews et al. (2001a) (and references therein) found the whole earth meteoroid mass flux in the meteor zone to be of the order 1.6 to $2.7 \times 10^{6} \mathrm{~kg} /$ year. Others find larger values (e.g. Hughes 1992) while Mathews et al. (2010) provide evidence of both direct ablation and fragmentation - suggestive of direct dust formation - of

\footnotetext{
* Correspondence: sarkhel.fph@iitr.ac.in

'Radar Space Sciences Laboratory, 323 Electrical Engineering East, The

Pennsylvania State University, University Park, PA, USA

${ }^{2}$ Space and Atmospheric Sciences, Arecibo Observatory, Center for Geospace

Studies, SRI International, Arecibo, Puerto Rico, USA

Full list of author information is available at the end of the article
}

incoming meteoroids in the meteor zone. These processes, the meteoroid mass flux arriving in the meteor zone as both ablated atomic metals and as dust, are widely accepted to be the major source of atomic $\mathrm{Na}$ (and $\mathrm{NaHCO}_{3}, \mathrm{Na}^{+}$, etc.) in mesosphere (Plane 2004). While Plane (2003), in examining Na chemistry, suggests that the sporadic enhancements in $\mathrm{Na}^{+}$concentrations can be correlated with meteor shower events, Plane et al. (2007) find that meteor showers produce a negligible change in atomic $\mathrm{Na}$. This suggests that the reservoir of $\mathrm{Na}$ in the MLT region is large compared to that represented in the diurnal meteoroid mass flux as well as in shower events thus suggesting that dynamics and chemistry are also important. Lidars with high time and range resolution have enabled direct observation of metals represented in short-lived meteor trails (Kane and Gardner 1993; von Zahn et al. 1999; Pfrommer et al. 2009). 
Bowman et al. (1969) first measured the vertical distribution of $\mathrm{Na}$ atoms using resonance lidar and, subsequently, systematic measurements were carried out over the globe. Lidar measurements of $\mathrm{Na}$ atom concentration over low latitude stations have been carried out for several decades (e.g. Clemesha et al. 1979; Taylor et al. 1995; Collins et al. 2002; Clemesha 2004; Sarkhel et al. 2009, 2010, 2012a). On occasion, the $\mathrm{Na}$ concentration profiles show enhancement by a factor of 2 or more over the usual background layer in a narrow altitude region of up to a few kilometer thickness. These layers are known as sporadic $\mathrm{Na}$ layer $\left(N a_{S}\right)$ (e.g. Clemesha et al. 1978) and often appear to be related to the ion layers called sporadic $\mathrm{E}\left(E_{S}\right)$. The generation of $N a_{S}$ in this case is believed to be neutralization of metallic ions accumulated (concentrated) within a narrow altitude region (sporadic E) by the wind shear mechanism (e.g., Mathews 1998). Several observations of $\mathrm{Na}_{S}$ have been reported (e.g. Kane et al. 1991; Fan et al. 2007; Dou et al. 2009) wherein they deal with the correlation of $N a_{S}$ events with $E_{S}$ events. In this context, it is also to be noted that high altitude sporadic metal layers (or high altitude metal layers) have been reported from several observational sites (e.g. Friedman et al. 2013, Höffner and Friedman 2004; Chu et al. 2011; Xue et al. 2013). Gao and Mathews (2014a,b) and references therein report on high altitude radar and optical meteors indicative of sputtering as a source of metal ions above the traditional meteor zone.

Kane et al. (2001) observed a rare type of sporadic $\mathrm{Na}$ layer structure over Arecibo, Puerto Rico. They suggested that these structures could be related to the occurrence of field-aligned ionospheric irregularities detected by a nearby VHF radar pointed towards the $\mathbf{k} \perp \mathbf{B}$ region to the magnetic north of Arecibo Observatory and concluded that Kelvin-Helmholtz (KH) billows were the cause. These structures are different from conventional $N a_{S}$ structures and often resemble the rare 'C-type' $\mathrm{Na}$ layer structures sometimes seen in lidargrams (e.g., Clemesha et al. 2004). $\mathrm{KH}$ billows are generally considered to occur due to dynamical instability with onset condition judged by the Richardson number $\left(R_{i}\right)$ (Richardson 1920) given by

$$
R_{i}(z)=\frac{N^{2}(z)}{(d u / d z)^{2}+(d v / d z)^{2}}
$$

where $u(z)$ and $v(z)$ are the zonal and meridional winds (in $\mathrm{m} / \mathrm{s}$ ) at an altitude $z$.

$N^{2}$ is the square of the Brunt-Väisälä frequency

$$
N^{2}(z)=\frac{g}{T(z)}\left[\frac{g}{C_{p}}+\frac{d T(z)}{d z}\right]
$$

where $T(z)$ is temperature at height $z$ (meters), $g$ is the acceleration due to gravity $\left(\mathrm{m} / \mathrm{s}^{2}\right)$, and $C_{p}$ is the molecular specific heat at constant pressure $\left(1,004 \mathrm{~J} \mathrm{~kg}^{-1} \mathrm{~K}^{-1}\right.$ for diatomic molecules like $\mathrm{N}_{2}$ and $\mathrm{O}_{2}$ ).

The dynamical instability may cause turbulence if the wind shear is sufficiently large. The canonical value of the Richardson number yielding dynamic instability is $R_{i}<0.25$. As is well accepted in the literature, wind shears in the MLT region play a critical role in sodium layer characteristics. For example, Pfrommer et al. (2009) found clear evidence for dynamic instability by direct observation of $\mathrm{KH}$ billows in the MLT region using a high resolution $\mathrm{Na}$ lidar. These dynamic instability processes are also responsible for generating various short-period structures (e.g. Sarkhel et al. 2012b).

Clemesha et al. (2004) also observed 'C-type' structures in the $\mathrm{Na}$ layer. However, they suggest an alternative to direct instabilities in creating these structures. Based on nearby simultaneous meteor wind measurements, they suggest that these 'C-type' structures might be the result of direct wind-shear distortion of preexisting clouds of enhanced sodium concentration (Nas) and advection of those spatial structures over the lidar site. They also conclude that there is limited evidence for the relationship between these 'C-type' structures and $E_{S}$. Hysell et al. (2004) shows an example of the complex structure of $E_{S}$ over Arecibo Observatory. This structure, sometimes associated with quasi-periodic echoes, may be the result of both horizontal and vertical convergence of ions (Mathews et al. 2001b). Mathews (1996) notes the interplay between $E_{S}$ and neutral $\mathrm{Na}$ layers and that the issue ultimately demands an instrument cluster to resolve.

Sridharan et al. (2009) observed rare complex structures in the Na layer over Gadanki (India) characterized by rapid enhancements of $\mathrm{Na}$ concentration that are completely different from the usual sporadic $\mathrm{Na}$ structures. They concluded that these complex structures could be due to the $\mathrm{KH}$ instability occurring in a region of strong wind shear. Of late, Sarkhel et al. (2012a) observed a frozen-in billow-like structure in the $\mathrm{Na}$ layer over Arecibo and found that it was likely created via dynamical instability processes. As this topic remains open and with the prior observations of these unusual structures over Gadanki and Arecibo, we are motivated to carefully examine additional Na lidargrams, in this case from Gadanki on the night of 18 to 19 March 2007. It should be noted that the $\mathrm{Na}$ lidar data on this night was reported in a different context in Sarkhel et al. (2010). The theme of the earlier paper was entirely different wherein they investigated the sensitivity of $\mathrm{Na}$ airglow intensity to the altitude-dependent collisional quenching that ultimately affects the $\mathrm{Na}$ airglow emission intensity. Based on available meteor wind radar observations from Thiruvananthapuram, India and available satellite-borne measurements, the goal of this communication is to investigate the physical mechanism(s) behind the occurrence of 
the observed unusual structure in the $\mathrm{Na}$ layer that has not been reported so far to the best of our knowledge.

\section{Methods}

$\mathrm{Na}$ atom concentration in the altitude range of 80 to 105 $\mathrm{km}$ was derived using the $\mathrm{Na}$ resonance lidar at the National Atmospheric Research Laboratory (NARL), Gadanki, India $\left(13.5^{\circ} \mathrm{N}, 79.2^{\circ} \mathrm{E}\right.$; dip lat $\left.6.3^{\circ} \mathrm{N}\right)$. A tunable dye laser, pumped by a Nd:YAG laser, is used in the $\mathrm{Na}$ lidar system operating at $50-\mathrm{Hz}$ pulsing rate with an output energy of $12 \mathrm{~mJ}$ per pulse at $589 \mathrm{~nm}$. The first lidar observations of the nighttime $\mathrm{Na}$ layer over Gadanki and the specifications of this Na lidar system are available in the literature (Bhavani Kumar et al. 2007a,b). For the uses herein, the 18 to 19 March 2007 $\mathrm{Na}$ concentration profiles are derived with an altitude resolution of $300 \mathrm{~m}$ (bin width of $2 \mu \mathrm{s}$ ) and temporal resolution of $2 \mathrm{~min}$.

In order to assess the effect of neutral atmosphere instability on the neutral $\mathrm{Na}$ layer, mesospheric horizontal wind profiles are also used in the present investigation. The wind measurements were carried out using the SKiYMET meteor wind radar (Hocking et al. 2001; Hocking 2005) situated at the Space Physics Laboratory (SPL), Thiruvananthapuram, India $\left(8.5^{\circ} \mathrm{N}, 77^{\circ} \mathrm{E}\right)$. This radar operates at $35.25 \mathrm{MHz}$, with a peak power of 40 $\mathrm{kW}$. The radar site is close to the magnetic equator. Hence, a special transmitting scheme has been worked out to avoid the echoes from the equatorial electrojet (EEJ). A detailed discussion of the transmitting scheme and the system specifications are given in Deepa et al. (2006). The horizontal wind structure was obtained by measuring the radial velocity with an accuracy of $5 \%$ or better for every acceptable meteor event and combining these measurements yielding an all-sky manner. The minimum elevation angle used was $20^{\circ}$. This corresponds to the radar volume of approximately $550-\mathrm{km}$ diameter at $100-\mathrm{km}$ altitude. The vector wind measurements were carried out in every 15 min with an altitude resolution of approximately $3 \mathrm{~km}$ within 82 - to $97-\mathrm{km}$ region.

The mesospheric temperature profiles needed for our neutral atmosphere instability calculations are obtained from the TIMED (Thermosphere Ionosphere Mesosphere Energetics and Dynamics) satellite. The altitude profiles of mesospheric kinetic temperature obtained by the SABER (Sounding of Atmosphere using Broadband Emission Radiometry) instrument onboard TIMED are additionally employed in this study (data source: http:// saber.gats-inc.com; v2.0). SABER uses the $15 \mu \mathrm{m} \mathrm{CO}_{2}$ terrestrial emission to retrieve pressure, which is then utilized to derive temperature with a maximum uncertainty of $10 \mathrm{~K}$ in the altitude range of 80 to $105 \mathrm{~km}$ (Mertens et al. 2001). SABER measurement locations are chosen nearest to the meteor wind radar observational site (SPL,
Thiruvananthapuram), which are depicted in Figure 1. The SABER measurement time used here was at about 01:30 IST (IST $=\mathrm{UT}+5.5 \mathrm{~h}$ ) on 18 to 19 March 2007.

\section{Data analysis}

Figure 1 shows a map of the Indian subcontinent depicting the locations of NARL and SPL. The SABER measurement locations are also shown in same figure. These locations are chosen based on the SPL, Thiruvananthapuram meteor radar observing site. For this event case study, two SABER profiles at different measurement locations were used; these measurements were carried out almost simultaneously (at approximately 01:30 IST).

The mesospheric temperature profile is used to calculate $N^{2}$, while Richardson number $R_{i}$ requires additional knowledge of wind shear. Altitude profiles of $R_{i}$ at different times during 18 to 19 March 2007 are calculated using the SABER temperature profiles and the SPL, Thiruvananthapuram meteor winds. It is to be noted that the SABER snapshot measurement of nocturnal mesospheric temperature is available only at around 01:30 IST. In this context, it is important to note that the average temporal variation in the nocturnal temperature over Gadanki (a low latitude station) during spring equinox (March) is only approximately $20 \mathrm{~K}$ in the altitude range of 80 to $105 \mathrm{~km}$ (Kishore Kumar et al. 2008). They present height-time contours of SABER-derived temperatures during the spring equinox (March and April) over the southern Indian subcontinent, which reveals that the average temperature during nighttime (16 to $24 \mathrm{UT}$ ) varies in over 180 to $200 \mathrm{~K}$ in the altitude range of 80 to $105 \mathrm{~km}$. However, the nocturnal temporal variation in mesospheric temperature is taken to be small as just outlined. Hence, the single approximately 01:30 IST, location-averaged, temperature profile obtained from SABER is used as a representative value during the interval of interest. As Thiruvananthapuram is also a low latitude station, the same temperature profile is (necessarily) adopted for this location. From these two datasets - using SPL, Thiruvananthapuram meteor wind profiles and the average temperature profile of SABER 1 and 2 (shown in Figure 1) - a height-time $R_{i}$ map is developed. As shown in Figure 1, the SABER 1 and 2 locations are separated by around $500 \mathrm{~km}$ while the variation in temperature between the locations is only $5 \%$ to $7 \%$ in the altitude range of 800 to $100 \mathrm{~km}$ (presented in Figure 2, to be discussed in the 'Results' section). Thus, the spatial variability between SABER 1 and 2 is expected to be small. Since the SPL, Thiruvananthapuram meteor radar site is approximately $600 \mathrm{~km}$ from the SABER 1 and 2 locations, a similar argument is taken for the radar site. That is, the snapshot temperature profiles are measured approximately $600 \mathrm{~km}$ away from radar site at 01:30 IST, we thus (necessarily) assume that the temperature profile 


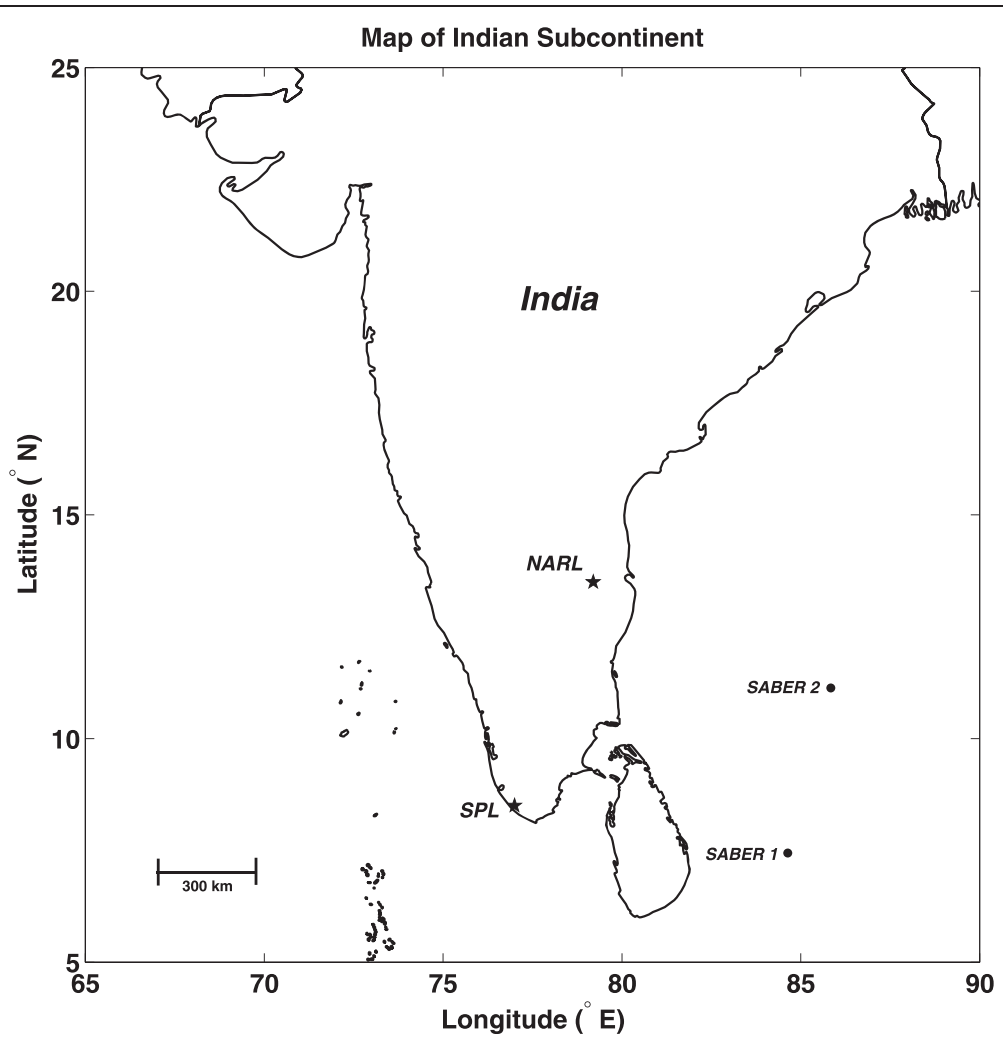

Figure 1 Locations of meteor wind radar, SABER measurement and Na lidar. Map of Indian subcontinent showing the locations of meteor wind radar at SPL, Thiruvananthapuram and Na lidar at NARL, Gadanki. SABER measurements locations are also depicted on the map.

in the radar volume is that of the SABER locations. We again note that meteor radar provides average wind over approximately $275-\mathrm{km}$ radius around the radar site. We thus used the average temperature profile for the calculation of Richardson number over Thiruvananthapuram.

The uncertainty in the meteor radar-derived horizontal wind is approximately $5 \mathrm{~m} / \mathrm{s}$ in the altitude range of 91 to $97 \mathrm{~km}$ and over the approximately $275-\mathrm{km}$ radius. Hence, when also considering the uncertainty in SABER temperatures of approximately $10 \mathrm{~K}$, the maximum uncertainty in computing $R_{i}$ is approximately 0.02 .

\section{Results}

Figure 3a displays the atomic $\mathrm{Na}$ height-timeconcentration map (or lidargram) for the night of 18 to 19 March 2007 over the 80 - to $105-\mathrm{km}$ altitude range above Gadanki. Figure 3b gives a detail of the 90- to $105-\mathrm{km}$ altitude region $\mathrm{Na}$ distribution on that night. As previously noted, this paper is prompted by the unusual sodium concentration structure resembling a mirror image of $\lambda$ (named as ' $\lambda_{\text {image }}$ ' henceforth) that is observed in the altitude range of 92 to $98 \mathrm{~km}$ over 21:30 to 22:00 IST. Of further interest is the net increase of the background $\mathrm{Na}$ atom concentration above $94 \mathrm{~km}$ after the occurrence of this structure. Figure $3 c$ gives the sequence of individual $\mathrm{Na}$ concentration profiles on that night. There is no apparent downward phase progression an acoustic gravity wave feature - after the structure appeared in the lidargram up to 00:00 IST and over the altitude range of 93 to $100 \mathrm{~km}$. Figure 3d shows the integrated column content between the base and top of the $\lambda_{\text {image }}$ structure (93 to $100 \mathrm{~km}$ ). The column content is observed to increase noticeably after the appearance of the structure until 22:30 IST. This increase is in addition to a steady column content increase through the whole observation period.

Figure 2 gives the individual SABER temperature profiles, SABER 1 and 2, during the night of 18 to 19 March 2007 at approximately 1:30 IST. The measurement locations are shown in Figures 1 and 2, and they reveal that the variation in temperature between SABER 1 and 2 is only $5 \%$ to $7 \%$ in the altitude range of 80 to $100 \mathrm{~km}$.

Figure 4a,b gives the SPL, Thiruvananthapuram meteor radar-derived zonal and meridional wind profiles for the 18 to 19 March 2007 observing period. It is interesting to note that the zonal wind is eastward (positive) and meridional wind is northward (positive) over 17:00 to 00:00 IST above 91-km altitude. Figure 4c shows the altitude variation of $R_{i}$ at different times over Thiruvananthapuram. $R_{i}$ is calculated using total wind 


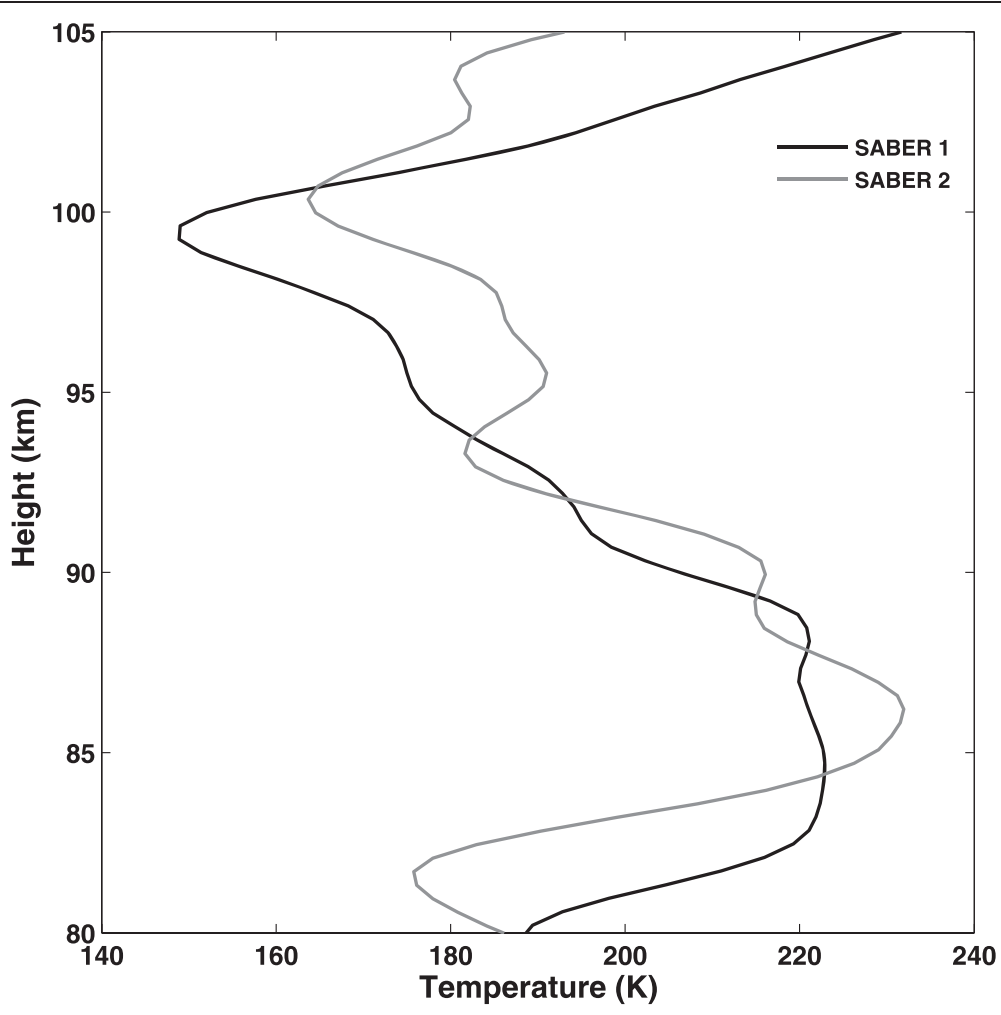

Figure 2 SABER temperature profiles for two locations (both the locations are shown in Figure 1).
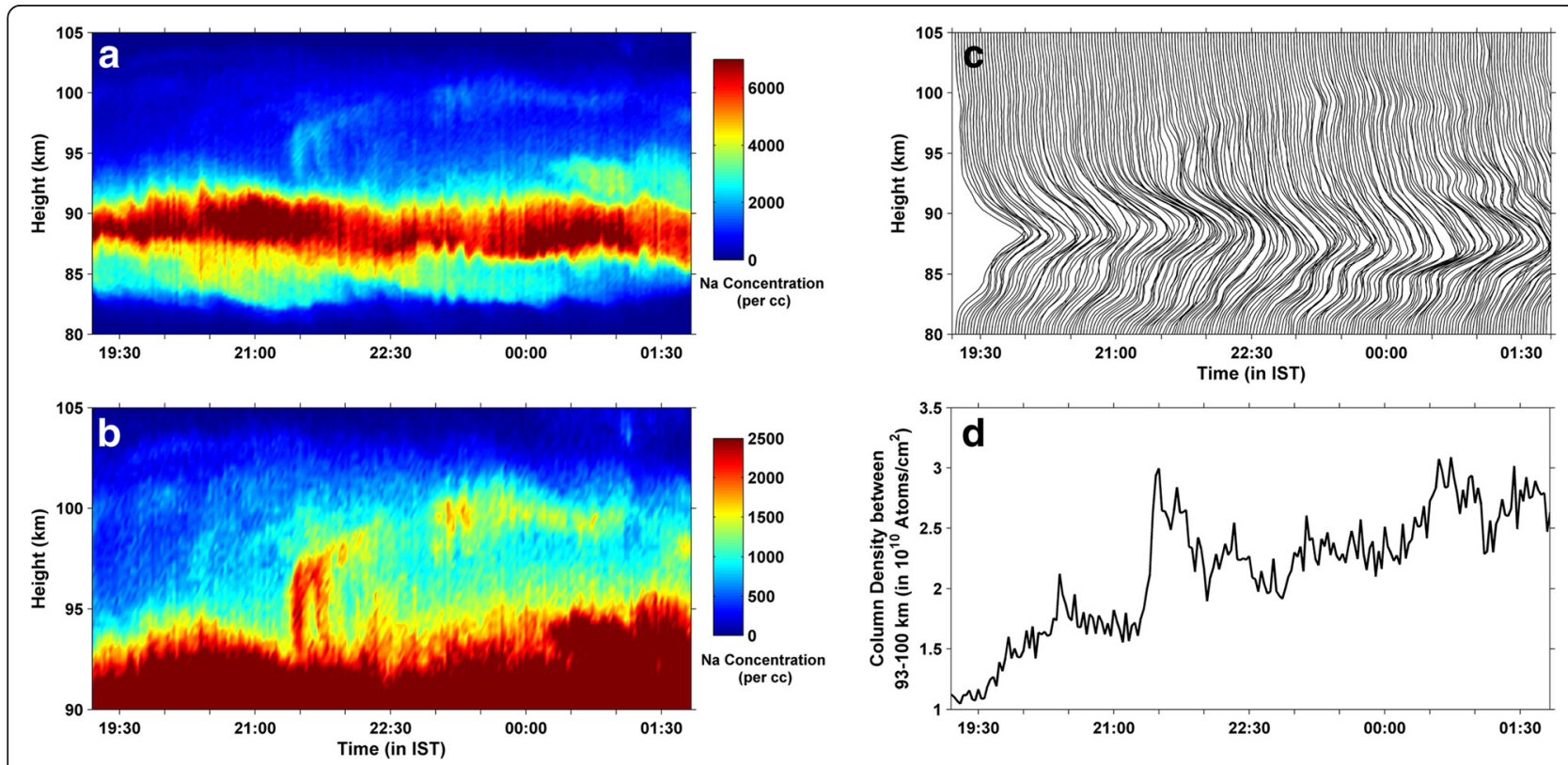

Figure 3 Sodium concentration on 18 to 19 March 2007 (NARL, Gadanki). (a) Height-time-concentration map (or lidargram) of the Na atoms during 18 to 19 March 2007 in the altitude 80- to 105-km range of over NARL, Gadanki. (b) Lidargram showing the distribution of Na atoms in the 90 - to $105-\mathrm{km}$ altitude showing the ' $\lambda_{\text {image' }}$ structure with concentrations exceeding 2,500 atoms $\mathrm{cm}^{-3}$ saturated to highlight the structure. (c) Sequence of Na concentration profiles. (d) The column density of $\mathrm{Na}$ atoms between 93 and $100 \mathrm{~km}$. 


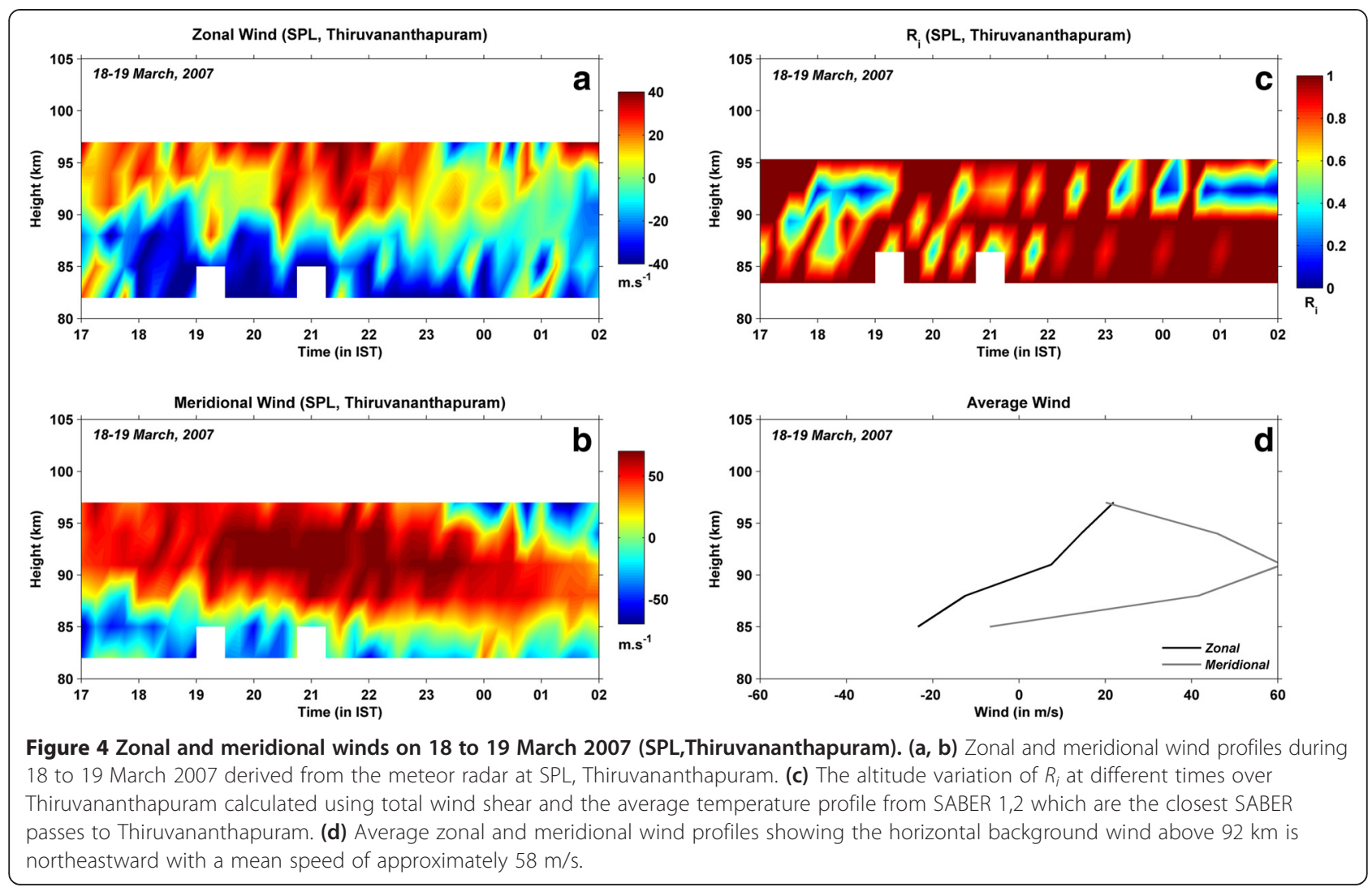

shear and the average temperature profile obtained using SABER 1,2 data, which are the closest SABER passes to Thiruvananthapuram (shown in Figure 1). It can be noted that $R_{i}$ remains less than 0.25 during 18:00 to 19:00 IST above $92 \mathrm{~km}$, which is likely to be an indication of $\mathrm{KH}$ billows. It has been also verified that the convective instability was absent on that night as the Brunt-Väisälä frequency $\left(N^{2}\right)$ derived at both SABER 1 and 2 locations were found to be positive throughout the entire region ( 80 to $105 \mathrm{~km}$ ). While $\mathrm{Na}$ lidar measurements over Thiruvananthapuram would have been ideal, we must address the lidar at Gadanki observational results per the generation of $\mathrm{KH}$ instabilities over this location using the Thiruvananthapuram meteor wind data. However, the $R_{i}<0.25$ altitude region inferred from the meteor radar winds and SABER winds reasonably matches the region over Gadanki where the ' $\lambda_{\text {image }}$ ' type structure was observed over 21:30 to 22:00 IST. While not proof, the $R_{i}<0.25$ region and the scale over which it is estimated together with the ' $\lambda_{\text {image }}$ ' structure suggests that the origin of the ' $\lambda_{\text {image }}$ ' type structure is in the generation (and the subsequent advection to the Gadanki area) of $\mathrm{KH}$ instabilities as we further address in the 'Discussion' section.

Figure $4 \mathrm{~d}$ gives the average zonal and meridional wind profiles. Importantly, the horizontal background wind above approximately $92 \mathrm{~km}$ is northeastward with a mean speed of approximately $58 \mathrm{~m} / \mathrm{s}$. Figure 5 highlights the zonal and meridional wind during 18:00 to 19:00 IST over Thiruvananthapuram when $R_{i}<0.25$. It can be noted that the zonal wind switches direction between eastward and westward above $95 \mathrm{~km}$ over the 18:15 to 18:45 IST period. In addition, it is predominantly westward at 18:30 IST except at $94-\mathrm{km}$ altitude where it is observed to be eastward. The direction of the meridional wind is unaltered during this time period, and the net wind vector is observed to be northeastward. These facts support the idea that the instability region over Gadanki is indeed advected towards Thiruvananthapuram and that the ' $\lambda_{\text {image }}$ ' $\mathrm{Na}$ layer structure is arguably a result of a $\mathrm{KH}$ billow that occurs in the inferred - and likely mesoscale sized - dynamic instability region over the southwestern Indian subcontinent.

\section{Discussion}

This section explores and discusses the role of various physical mechanisms that can generate the ' $\lambda_{\text {image }}$ ' structure observed in the lidargram (Figure 3 ) presented in the above section.

\section{Role of dynamical instability and advection}

In order to understand the occurrence of the ' $\lambda_{\text {image }}$ ' structure in the lidargram shown in Figure 3, we assembled all available data to determine if we could identify a 

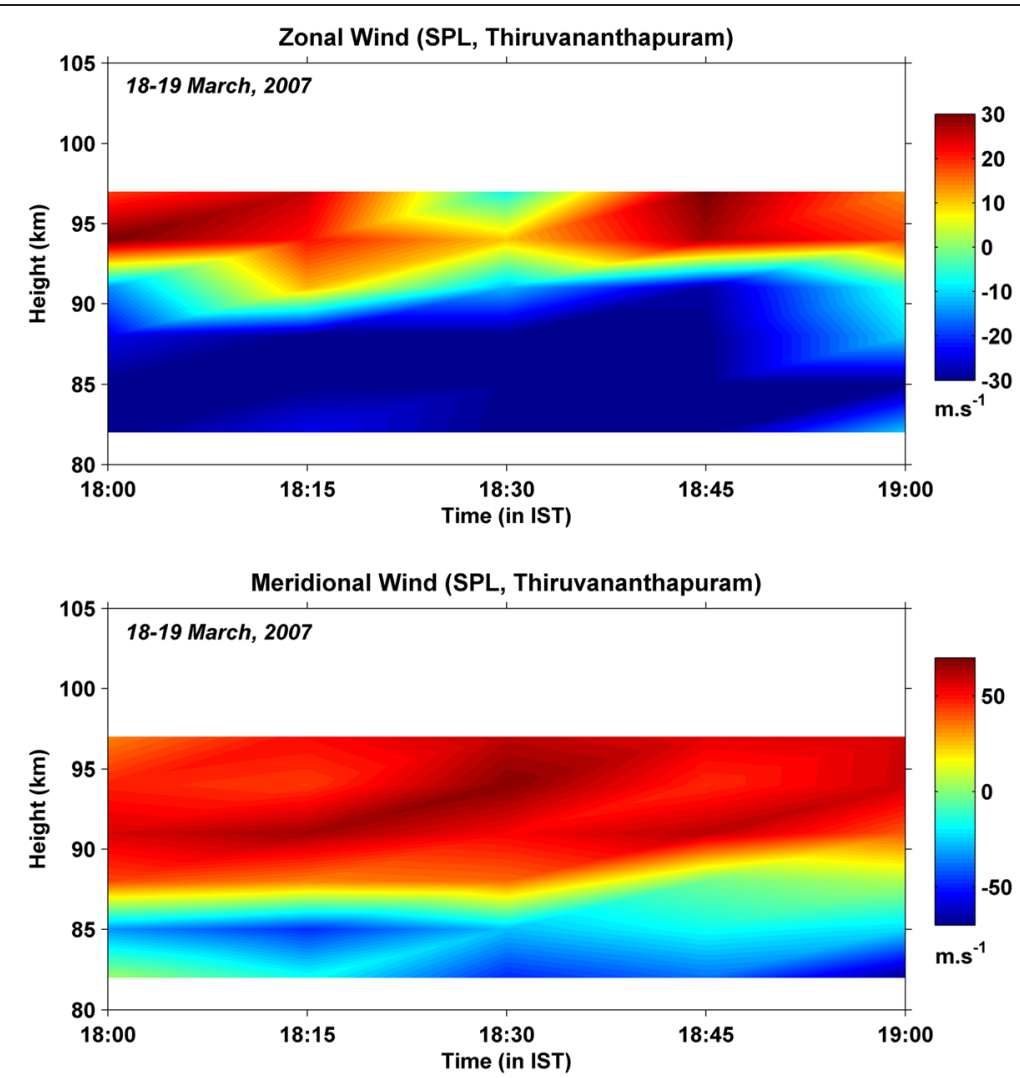

Figure 5 Zonal and meridional winds during 18:00 to 19:00 IST. This highlights the zonal (upper panel) and meridional (lower panel) wind during 18:00 to 19:00 IST when Ri remains less than 0.25 , conditions conducive for the growth of dynamical instabilities.

possible source of this structure. Atmospheric winds and temperatures in the MLT region are necessary to investigate the possible role of convective or dynamic instabilities. In the absence of wind measurement over/nearby Gadanki, zonal and meridional wind profiles over Thiruvananthapuram are used in the present investigation (location is shown in Figure 1). Based on the horizontal winds and SABER temperature profiles, the altitude variation of $R_{i}$ is derived at different times and found to be predominantly less than the canonical instability threshold of 0.25 during the 18:00 to 19:00 IST period (Figure 4c) - a condition which is conducive for the generation of $\mathrm{KH}$ billows. It is important to note that the average background wind above $92 \mathrm{~km}$ is northeastward with magnitude of approximately $58 \mathrm{~m} / \mathrm{s}$. As Gadanki is northeast of Thiruvananthapuram, the atmospheric background condition is suitable not only for generation of KH-billow structures but also for the (in this case necessary) advection of these billows towards Gadanki. As the beam-width of SKiYMET meteor wind radar is several tens of degrees (Hocking 2005), the derivation of horizontal wind profiles is necessarily averaged over a vast horizontal area of the MLT region. Hence, these winds are taken to prevail over a wide region in southern part of India (as is the SABER temperature determination) and thus that the KH-billow structure we suspect to have developed during 18:00 to 19:00 IST over Thiruvananthapuram to have been advected to Gadanki (possibly) without further modification till 23:00 IST. The important point here is that conditions are conducive for $\mathrm{KH}$-billow formation and for advective transport of these structures from southern India to Gadanki.

It is to be noted that the volume-averaged meteor radar wind data is dominated by large-scale temporal changes instead of spatial changes within the observing volume. The changes in the horizontal wind during 18:00 to 19:00 IST (shown in Figure 5) suggest that the generation and the temporal evolution of the proposed $\mathrm{KH}$-billow structure occur during this interval (to be discussed later in detail in Figure 6a). However, in the absence of strong shear in the horizontal wind after this time, it is assumed that the structure, thus formed, remains temporally less affected and is spatially advected in the northeastward direction as a result of winds in the direction leading to its appearance over Gadanki. Additionally, it is to be noted that the meteor radar, given the volume averaging, does not reveal any information on the KH-billow structure and only provides the 


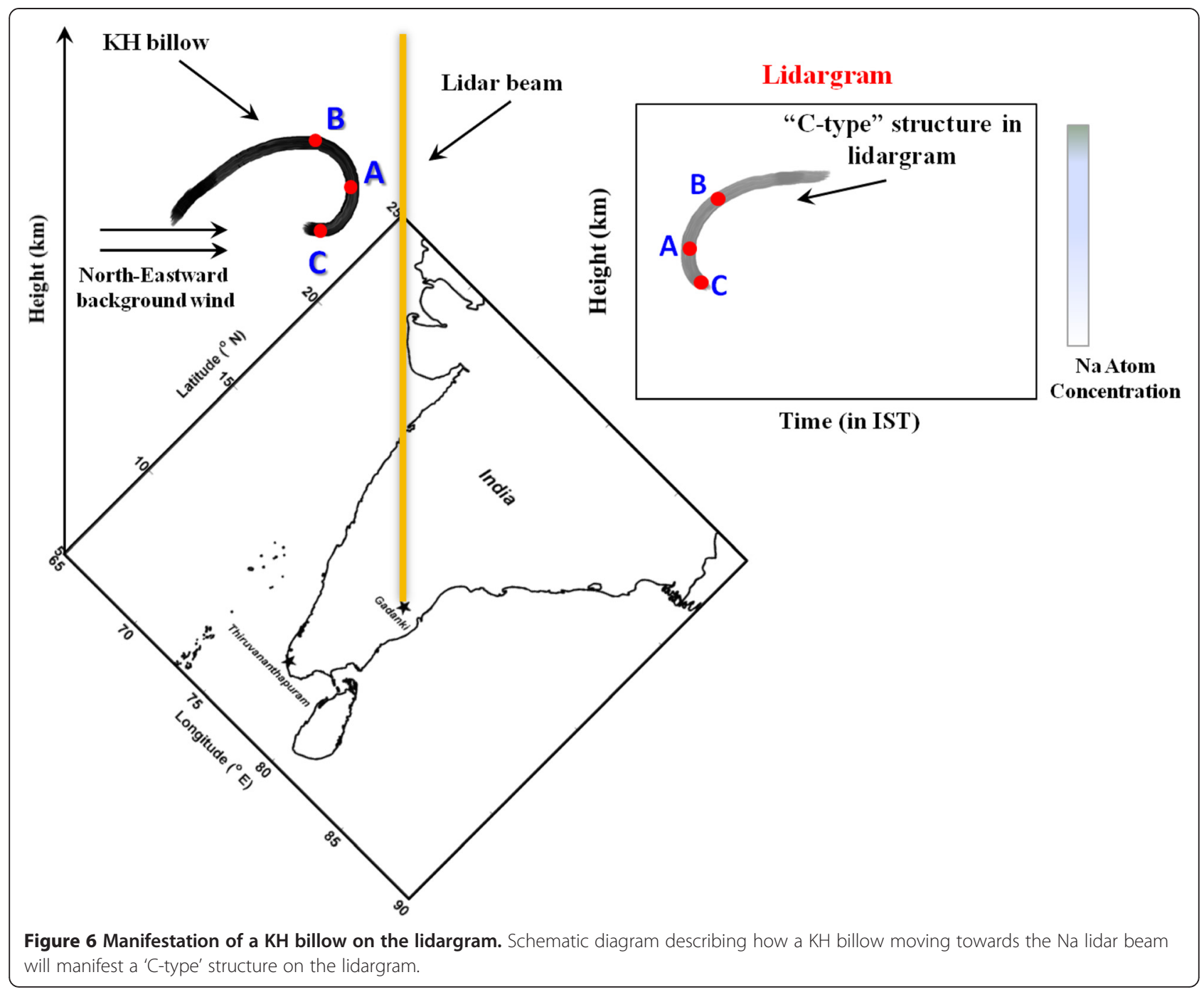

information on the wind, one of the parameters for determining dynamical instability. The generation and evolution of the KH-billow structure, as mapped into the $\mathrm{Na}$ profile, and its subsequent transport in nearly 'frozen-in' condition is only a proposition and not a proof. At the core of our argument, this hypothesis does appear to explain the Na lidar observation over Gadanki.

Given our hypothesis whether the $\mathrm{KH}$ billow will be transported by background wind to reach the $\mathrm{Na}$ lidar location can now be investigated further. Based on the horizontal background wind of approximately $58 \mathrm{~m} / \mathrm{s}$ above $92 \mathrm{~km}$ averaged throughout the entire observational period (17:00 to 02:00 IST), the travel time for $\mathrm{KH}$ billow to reach Gadanki around - $600 \mathrm{~km}$ away from Thiruvananthapuram - is $3 \pm 1 \mathrm{~h}$. The uncertainty involved in estimating travel time is calculated based on the standard deviation of horizontal wind of approximately $17 \mathrm{~m} / \mathrm{s}$ during entire observational period above $92 \mathrm{~km}$. Interestingly, this travel time nearly matches with the time difference between the conjectured occurrence of $\mathrm{KH}$ billow (dynamical instability conditions) over Thiruvananthapuram and the appearance of the ' $\lambda_{\text {image }}$ ' structure in the Na layer over Gadanki. Thus, based on these observations, it is reasonable to assume that the formation and advection of KH billows left a unique signature on the $\mathrm{Na}$ layer. It is also to be noted that $\lambda_{\text {image }}$ structure appeared in the $\mathrm{Na}$ layer during 21:30 to 22:00 IST (Figure 3) before the second wind reversal that occurred at $97 \mathrm{~km}$ during 23:30 to 00:00 IST (Figure 4), which would have no effect on the already formed $\lambda_{\text {image }}$ structure over Gadanki. A scenario for formation of the sodium ' $\lambda_{\text {image }}$ ' structure due to $\mathrm{KH}$ billows is addressed next.

It is important to note that $\mathrm{Na}$ lidar records horizontally narrow vertical profiles of $\mathrm{Na}$ atom concentration as a function of time. Thus, the lidargram represents a time history of the vertical distribution of $\mathrm{Na}$ atoms in a narrow cylindrical volume over the lidar location. The lidargram of course includes the effects of neutral 

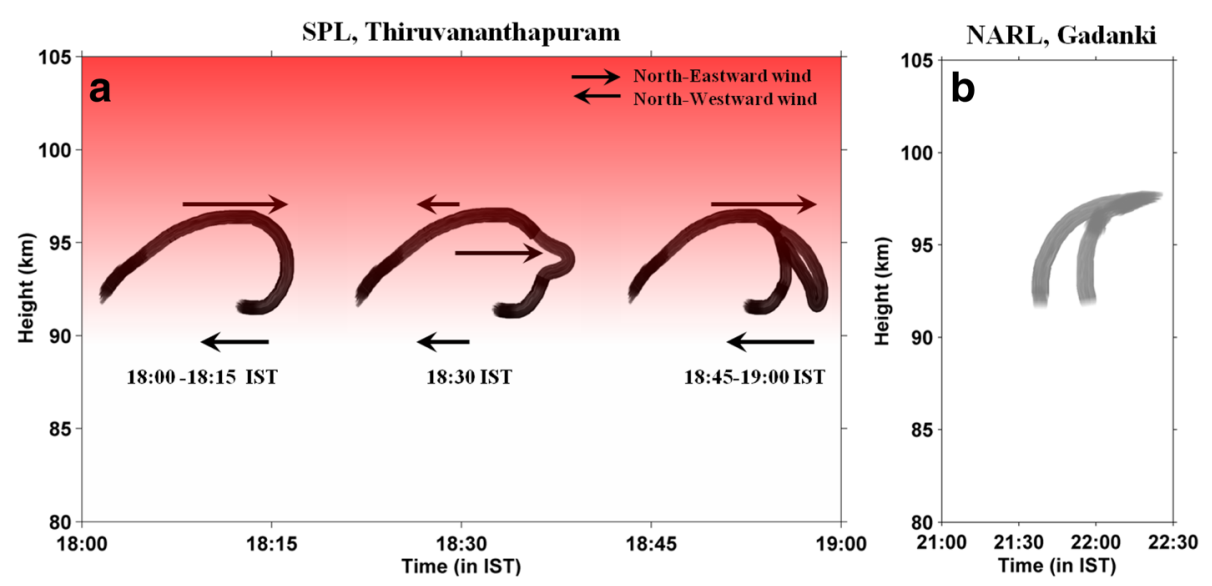

Figure 7 Evolution and advection of the KH billow under favorable background condition. (a) Schematic diagram of a possible KH-billow evolution scenario given the winds observed at Thiruvananthapuram. The false color background gradient schematically underscores the complex chemical/dynamical interplay in producing the Na distribution in the MLT region. (b) Pictogram describing how the deformed KH billow is advected with background wind and created a ' $\lambda_{\text {image }}$ 'type structure in the lidargram over Gadanki.

atmosphere dynamics on the $\mathrm{Na}$ layer as these atoms have a long lifetime relative to the evolution of atmospheric dynamics and they are collisionally wellembedded in the atmosphere. Based on typical electron concentration (approximately 3,000 electrons $\mathrm{cm}^{-3}$ ), Sarkhel et al. (2012a) estimated the rate at which the $\mathrm{Na}$ atoms ionize would be approximately $3 \times 10^{-6} \mathrm{~s}^{-1}$, which corresponds to a lifetime of neutral $\mathrm{Na}$ atoms of more than a day. This is supported by $\mathrm{Xu}$ and Smith (2003) wherein they have shown that the chemical lifetime of mesospheric Na atoms is more than a day in the MLT region, which is much larger than the transport time considered in our hypothesis. Hence, any Na-layer temporal variation on the scale of a few hours is predominantly due to dynamical effects in the $\mathrm{Na}$ layer where background horizontal wind and its shear play important roles. Thus, any horizontal structures, generated in the observed vertical $\mathrm{Na}$ profile by winds, will be translated into temporal variations of lidargram.

Kane et al. (2001) describe 'C-type' structures observed in the Na layer on several occasions. They suggested this type of structure could be caused by wave breaking or $\mathrm{KH}$ billows and could be generated in the Na layer due to strong wind shear. However, Clemesha et al. (2004) argued that advection could possibly generate 'C-type' structures in the $\mathrm{Na}$ layer. They describe a scenario wherein any $\mathrm{Na}$ cloud advected with the horizontal wind can be elongated via the prevailing wind and will be manifested as a 'C-type' structure in the lidargram. The schematic diagram in Figure 7 explains how a KH-billow structure can imprint a ' $\mathrm{C}$-type' structure in the lidargram. As described in the figure, the three points 'A,' 'B', and ' $\mathrm{C}$ ' on the billow whose curvature is facing towards the lidar beam will manifest as a 'C-type' structure. As discussed earlier, the lidargram represents a time history of vertical distribution of $\mathrm{Na}$ atoms over the lidar location. Hence, the point ' $\mathrm{A}$ ' on the advecting billow will appear first on the observed 'C-type' structure relative to points ' $\mathrm{B}$ ' and ' $\mathrm{C}$ ' that occur later.

In the present investigation, $R_{i}$ remains less than 0.25 during 18:00 to 19:00 IST as a consequence of strong wind shear and hence indicates the possible generation of $\mathrm{KH}$ billow. The overturning shape of these billows also depends on the direction of winds. In order to test this hypothesis, we critically observe the direction of zonal and meridional wind profiles during the time of interest. The horizontal winds do reveal remarkable features. As shown in Figure 5, the zonal wind above 91 $\mathrm{km}$ is eastward and the meridional wind is northward during 18:00 to 18:15 IST and 18:45 to 19:00 IST. A significant wind reversal is observed at approximately 18:30 IST wherein the zonal wind is predominantly westward except for a altitude-narrow region near $94 \mathrm{~km}$ altitude where it is eastward (note again that the meteor radar winds are assembled over a relatively large volume). The meridional wind direction is unchanged during this time period. However, the meridional wind magnitude at 94 $\mathrm{km}$ is observed to increase to $68 \mathrm{~m} / \mathrm{s}$ at approximately 18:30 IST - this is more than 1.5 times higher than that during 18:00 to 18:15 IST and 18:45 to 19:00 IST. Hence, the horizontal wind at $94 \mathrm{~km}$ is northeastward with higher magnitude and northwestward at other altitudes at 18:30 IST. This sudden wind reversal over a limited altitude region generates a strong wind shear. This interesting and perhaps unique phenomenon - that occurs over a significant volume - leads to the possible shape of the hypothesized evolving $\mathrm{KH}$ billow.

Figure 6 represents our schematic depiction of how a $\mathrm{KH}$ billow generated and evolving in the observed strong wind shear might result in the observed ' $\lambda_{\text {image }}$ ' type 
structure. Again, note that the observed horizontal wind was northeastward above $93 \mathrm{~km}$ and northwestward below this altitude during the 18:00 to 18:15 IST period. That is, given the observed winds, the billowoverturning feature will face towards the northeastward as is sketched in Figure 6a. Then, the KH billows is subject to a wind reversal at approximately 18:30 IST that could produce an additional 'fold' in billow structure due to the net wind being northeastward at $94 \mathrm{~km}$ with a higher magnitude and northwestward elsewhere. As is well accepted in the literature that $\mathrm{KH}$ billows, generated within a particular altitude region, expand both horizontally and vertically. In the present case, we suggest that the $\mathrm{KH}$ billow is generated at approximately $93 \mathrm{~km}$ where we infer that $R_{i}<0.25$ - the wind reversal takes place just above the altitude region where the billows are likely generated. Additionally, the background winds during 18:00 to 18:15 IST period favor the evolution and expansion of this $\mathrm{KH}$ billow. In particular, when the extended portion of the billow encounters the wind reversal region, it - under our hypothesis - undergoes deformation due to the northwestward wind. This peculiar wind pattern at $94 \mathrm{~km}$ during 18:30 IST deforms the shape of the $\mathrm{KH}$ billow and creates a small bulge or outward notch at $94 \mathrm{~km}$ which is conceptually drawn in Figure 6a. This bulge will be eventually elongated outward due to strong wind shear experienced during 18:45 to 19:00 IST. The protruding notch will subsequently overturn as a consequence of shear and enhancement of the northeastward wind at the height region around the notch similar to the condition prevalent during 18:00 to 18:15 IST. The possible shape of the bifurcated KH billow at 18:45 to 19:00 IST is indicated in Figure 6a. The curvature of the elongated notch will be northeastward similar to the original curvature of the $\mathrm{KH}$ billow adjacent to the overturned notch. How this structure may be translated or mapped into a lidargram is indicated in Figure 6b. To summarize, we suggest that this deformed KH-billow structure, generated during 18:00 to 19:00 IST over Thiruvananthapuram region, was then advected in the northeastward direction having developed more folder that was revealed subsequently as it crossed the field-of-view of the $\mathrm{Na}$ lidar over Gadanki.

Given the observed wind structure, the deformed $\mathrm{KH}$ billow traveling with mean speed of approximately 58 $\mathrm{m} / \mathrm{s}$ will reach the lidar site after $3 \pm 1 \mathrm{~h}$. This study suggests that such conditions can last for a few hours, thus yielding an estimate of the lifetimes of the $\mathrm{KH}$ billow which is generated and deformed during 18:00 to 19:00 IST interval and can then be nearly 'frozen-in' and advected along with the mean wind in the absence of strong shears. Sarkhel et al. (2012a) observed similar billow-like structures in the $\mathrm{Na}$ layer over Arecibo, Puerto Rico. They concluded that strong wind shear made the region dynamically unstable and was likely responsible for the observed structure in the $\mathrm{Na}$ layer that were observed in the lidargram for about $3 \mathrm{~h}$. This structure - while still evolving - would likely be transported some distance by the overall background wind.

Since the Na layer is embedded in the neutral atmosphere, any structure/instability created in the neutral atmosphere will also be mapped into the $\mathrm{Na}$ layer. As demonstrated in Figure 6, the KH billow whose curvature is faced towards the lidar beam will appear as 'C-type' structure in the lidargram. Since Gadanki is northeast of Thiruvananthapuram, a KH-billow structure, whose overturning shape is towards northeastward, will face towards the lidar beam. Hence, it will imprint a 'C-type' structure in the lidargram. As conceptually described in Figure 6a, the bifurcated $\mathrm{KH}$ billow that continues to 'fold' may develop a more complex structure facing towards lidar beam and may resemble the lidargram structure shown in Figure 6b. That is, these two adjoining 'C-type' structures, as a whole, then manifest a ' $\lambda_{\text {image }}$ ' structure in the lidargram.

The detection of any $\mathrm{Na}$ layer structures depends on the chemical lifetime of $\mathrm{Na}$ atoms, which must be large compared to the typical time scale of the dynamical events. Thus, once a KH-billow structure is generated due to favorable background conditions, it should be traceable using a Na lidar. This conducive atmospheric condition is achieved when $R_{i}<0.25$ which, in turn, depends on the altitude profiles of horizontal winds and temperature. It must be noted that the meteor wind radar, which measures altitude profiles of the horizontal wind, is not capable of detecting $\mathrm{KH}$ billow directly. The meteor wind radar only indicates the presence of wide-scale wind shears necessary for the generation of $\mathrm{KH}$ billow. In order to detect KH-billow structures in mesosphere, an instrument such as Na lidar is needed. Hence, the fact that $R_{i}>0.25$ after 19:00 IST over Thiruvananthapuram does not necessarily mean that the $\mathrm{KH}$ billow, generated during 18:00 to 19:00 IST, has vanished. Instead, it may indicate that the background condition is simply not conducive for further generation of $\mathrm{KH}$ billows. Our hypothesis is that the KH-billow structure (and its effect on the Na layer), once generated, remains more or less intact in the atmosphere for, perhaps, a few hours. This hypothesis is supported by the previous observations of billows in the $\mathrm{Na}$ lidar data over Arecibo that were seen for at least $3 \mathrm{~h}$ of observing period (Sarkhel et al. 2012b). Such structures can move with the mean wind and reaches the $\mathrm{Na}$ lidar location where it is detected.

In the next subsections, we will be exploring other plausible scenarios which could be responsible for modification of the $\mathrm{Na}$ layer and thus creating the ' $\lambda_{\text {image }}$ ' structure in the lidargram. 


\section{Role of gravity waves}

The possible role of gravity waves in the generation of these structures is considered next. A steady increase in column density, between the base and top of the $\lambda_{\text {image }}$ structure (93 to $100 \mathrm{~km}$ ) that continues to the end of the observation period is noted in Figure 3d. This feature might be related to long-period gravity waves with a dominant time period of fluctuation of approximately 88 min. However, the $\mathrm{Na}$ column density increases noticeably after the occurrence of the structure until 22:30 IST that may also indicate vertical overturning - due to the billows formation - whereby the $\mathrm{Na}$ content from the main layer is transported up into the region directly above. Whether this increase in $\mathrm{Na}$ abundance until 22:30 IST is due to gravity waves can be investigated. As revealed from Figure $3 \mathrm{c}$, the sequence of $\mathrm{Na}$ concentration profiles on that night does not reveal any downward phase progression up to 23:30 IST in the altitude range of 93 to $100 \mathrm{~km}$ after the structure appeared. Hence, it seems unlikely that the increase in column abundance during 21:00 to 22:30 IST is due to the effect of gravity waves propagating through the main $\mathrm{Na}$ layer. It remains possible, or perhaps even likely, that this increased column content is associated with the creation of the $\mathrm{KH}$ billow structure, a consequence of dynamical instability. Moreover, the main layer is centered around $90 \mathrm{~km}$ and shows the influence of wave activity during the entire observation. Thus, the $\lambda_{\text {image }}$ structure is not strongly related to the layer at $90 \mathrm{~km}$ and occurs only for short duration as compared to the main layer evolution. All these phenomena strengthen the hypothesis of the nearly 'frozen-in' KH-billow structure, which was created in the southwestern part of India due to appropriate atmospheric conditions and then transported along with the northeastward background wind which might have created the ' $\lambda_{\text {image }}$ ' structure in the lidargram over Gadanki.

\section{Role of sporadic-E activity}

While we conclude that dynamical instability led to the observed $\lambda_{\text {image }}$ structure, the possible relationship between the $\mathrm{Na} \lambda_{\text {image }}$ structure and $E_{S}$ is examined next. Clemesha et al. (2004) found weak correlation between these 'C-type' structures and $E_{S}$. Their conclusion is that the wind plays a major role creating the structure instead of conversion of $\mathrm{Na}^{+}$in $E_{S}$ to neutral Na. It is important to note that the region where the ' $\lambda_{\text {image' }}$ structure appeared is aeronomically very complex. The effect of atmospheric dynamics and $\mathrm{Na}$ ion-molecular chemistry is necessarily coupled together. The false color background gradient in Figure 6a schematically underscores the complex chemical/dynamical interplay in producing the Na distribution in the MLT. As the lifetime of $\mathrm{Na}^{+}$ions below $90 \mathrm{~km}$ is a few seconds (Daire et al. 2002), the recombination of $\mathrm{Na}^{+}$ions and electrons produces neutral $\mathrm{Na}$ atoms which are then embedded into the background atmosphere. Thereafter, the neutral $\mathrm{Na}$ layer follows the background atmosphere wherein dynamics plays major role. On the contrary, recombination of $\mathrm{Na}^{+}$ions and electrons occurs slowly above 100 $\mathrm{km}$. As a consequence, the lifetime of $\mathrm{Na}^{+}$ions increases to a few hours at this height region. Thus, the neutral $\mathrm{Na}$ layer produced by neutralization of $\mathrm{Na}^{+}$ions into $\mathrm{Na}$ atoms retains the memory of its ion layer and hence $E_{S}$. That is, any structure related to $\mathrm{Na}^{+}$ions will map into the neutral $\mathrm{Na}$ layer on a few hour time scale. Sarkhel et al. (2012a) observed high altitude (>102 km) billows in the neutral $\mathrm{Na}$ layer wherein they discussed that such structures in the neutral $\mathrm{Na}$ layer can be associated with the underlying ion layer during strong $E_{S}$ events for which ion concentration often exceeds $10^{4}$ ions.cm ${ }^{-3}$. In the intermediate altitude region (90 to $100 \mathrm{~km}$ ), we encounter the most complex interaction with both neutral $\mathrm{Na}$ and $\mathrm{Na}$ ions playing comparable roles. The lifetime of $\mathrm{Na}^{+}$ions ranges from a few minutes to tens of minutes (Daire et al. 2002). Therefore, the neutral Na layer will have a limited memory of $E_{S}$ where the presence of sufficient wind shear can generate $E_{S}$ layers (e.g. Mathews 1998). That is, since the $\mathrm{Na}^{+}$ions in the MLT region are partially collisionally coupled to neutral atmosphere, structures such as $\mathrm{KH}$ billows generated due to strong wind shear in the neutral atmosphere also may share features exhibited in $E_{S}$ layer structure. Thus, as the neutral $\mathrm{Na}$ layer and $E_{S}$ layers may share a common origin in the atmospheric wind system, it is difficult to exclude $E_{S}$ layer influence on the sodium distribution. In any case, with the absence of any ionosonde observations close to the lidar location during these observations, it is difficult to comment further on the occurrence/influence of $E_{S}$ layer over Gadanki region. Sporadic-E layers are related to the neutral enhancements via ion-neutral coupling (Raizada et al. 2011, 2012), any structure-like appearance of billow-like features are usually linked to dynamical instabilities (Sarkhel et al. 2012b). In order to address this aspect comprehensively, further investigations involving instrument clusters are needed (Mathews 1996).

The next subsections are dedicated to explain the valid assumptions that are used in the present investigation. The justifications behind such assumptions are also discussed in detail. We have also explored the limitations while formulating the hypothesis based on the available data set.

\section{Assumptions and their justifications}

We have necessarily calculated the time-resolved $R_{i}$ from temporally variable wind data and a snapshot temperature profile obtained approximately $600 \mathrm{~km}$ from the lidar site. We simply note the assumption that the temporal variation 
of temperature is not expected to be significant enough to alter the conclusion of the paper. As discussed earlier, the spatial variability between SABER 1 and 2 is not significant and this is taken as a proxy for changes, or rather the lack of change, in temperature with time. We have also verified the differences between the Richardson numbers derived using individual SABER 1, SABER 2, and average SABER 1,2 (which is already in Figure 4c) temperature profiles. We have observed that the $R_{i}$ 's are different for different temperature profile during 18:00 to 19:00 IST. However, they still remain less than 0.25 above $92 \mathrm{~km}$ during the abovementioned time. Therefore, the assumption that the spatial variation between SABER 1 and SABER 2 temperature profiles is not significant is fairly justified and we have thus used the average SABER 1,2 temperature profile to calculate the Richardson number.

The work of Kishore Kumar et al. (2008) indicates that the average nocturnal temporal variation of temperature in the altitude range of 80 to $105 \mathrm{~km}$ is approximately $20 \mathrm{~K}$ during spring equinox (March and April) over southern part of Indian subcontinent. Friedman and Chu (2007) also report that the standard deviation of temperature at a given upper mesosphere altitude is less than $20 \mathrm{~K}$ and is due to tides during March over Arecibo (a low latitude station) - this is also not very significant. Since $R_{i}$ is calculated based only on snapshot temperature profile, there can be an additional variability in $R_{i}$ due to variation in temperature during the night. Owing to the lack of measurement of the temporal variation of temperature at a given altitude over Thiruvananthapuram, it is not possible to comment on the variability of $R_{i}$ due to the temperature variation. The present work is based on the assumption that the temperature does not change significantly during the interval of generation of the $\mathrm{KH}$ billow over Thiruvananthapuram and subsequent propagation to Gadanki.

\section{Limitations}

In addition, the limitation of the available data set does not allow us to study the influence of small-scale horizontal/vertical variability - due largely to acoustic gravity waves - for this case. Short-scale, wave-related variability may change the local temperature and wind fields. However, the data provided in the manuscript is the best available data set that can be used to study possible mechanisms for generation of the observed $\lambda_{\text {image }}$ structure. While we cannot rule it out, there is no evidence that the temporal/horizontal variation of temperatures is not significant. However, the altitude variation of temperature is important, along with wind shears, in creating instabilities. Therefore, the vertical temperature gradient is an important parameter as it is used to calculate Brunt-Väisälä frequency and Richardson number. As discussed earlier, Friedman et al. (2003) reports that the nocturnal temperature variation at a given altitude in the MLT region is small over the low latitude site, Arecibo Observatory (latitude: $18.6^{\circ} \mathrm{N}$ ). Hence, we assume that temporal variation of the vertical gradient of temperature will also be small. Therefore, ignoring the temporal variation of the vertical temperature gradient at a given altitude in the MLT region is reasonable.

There are two other limitations in the present paper that could not be addressed due to lack of supporting observations. These are the possible effects of 'fieldaligned irregularity' and 'gravity wave ducting'. In the absence of collocated HF/VHF radar measurements, it is difficult to explore the impact of the field-aligned irregularities on the structures in the $\mathrm{Na}$ layer. The lack of imaging observations also does not allow investigation of the role of acoustic gravity wave ducting as horizontal phase speed and wavelength are unknown. A vertically propagating gravity wave can be ducted in a region where $m 2>0$ ( $m$ is the vertical wave number) and is bounded by regions of evanescence $(m 2<0)$ (e.g., Walterscheid et al. 2000). However, Sarkhel et al. (2012a) inferred that the ducted gravity waves are unlikely to generate a particular frozen-in billow-like structure in the $\mathrm{Na}$ layer reported in that work.

Despite the obvious limitations, the present investigation strongly suggests the importance of dynamical phenomena such as $\mathrm{KH}$ instabilities in the upper mesosphere and their likely role in the generation of complex structures, such as the ' $\lambda_{\text {image }}$ ' structure shown in Figure 3, in the $\mathrm{Na}$ layer. The multi-instrument observations reported here suggest how a bifurcated $\mathrm{KH}$ billow (and the embedded $\mathrm{Na}$ content) generated in the southwestern part of India due to wind shears - along with appropriate vertical temperature gradient - and advected by the background wind towards the northeast is consistent with the unusual structure observed in the Na layer. In the absence of measurements that are closely separated in space, the present explanation is only suggestive in nature.

\section{Lifetime of the deformed KH billow}

Despite the limitations due to the lack of cluster of instruments and coordinated measurements, our effort on the hypothesis of generation of the ' $\lambda_{\text {image }}$ ' structure in the lidargram brings out an important parameter that should be addressed: the lifetime of deformed KH billow. Our investigation poses a question: Can the deformed $\mathrm{KH}$ billow have a few hours lifetime? As already discussed, Pfrommer et al. (2009) found clear evidence of $\mathrm{KH}$ billows in the MLT region using a high resolution $\mathrm{Na}$ lidar. However, they observed $\mathrm{KH}$ billows in the lidargram only for a few minutes. As described by Hecht et al. (2005), the lifetime of such KH billows is a few tens of minutes. Theoretical studies by Fritts et al. (1996) and Palmer et al. (1996) show that the lifetime and evolution 
of such $\mathrm{KH}$ billows and their subsequent dissipation are complex and far less understood.

In recent times, the $\mathrm{Na}$ lidar observations and investigations on the manifestation of the $\mathrm{KH}$ billows in the $\mathrm{Na}$ layer brought the attention among the researchers. A few observations of 'C-type' structures in the lidargram from different locations bring out the existence of $\mathrm{KH}$ billows in the Na layer (Kane et al. 2001; Sridharan et al. 2009). All the observations reveal that the lifetime of the structures is $30 \mathrm{~min}$ to $2 \mathrm{~h}$. As explained by Clemesha et al. (2004), the occurrence of the 'C-type' structure in the lidargram is a result of wind-shear distortion of preexisting clouds of enhanced $\mathrm{Na}$ concentration. Kane et al. (2001) and Sridharan et al. (2009) suggested that KH billows play important role in the formation of 'C-type' structures that appeared in the lidargram. These observations indicate that the background wind and atmospheric conditions play crucial role in the evolution and sustenance of the $\mathrm{KH}$ billows in the MLT region. In the present case study, the KH billow has been hypothesized to be generated and deformed during 18:00 to 19:00 IST over Thiruvananthapuram. Further evolution and deformation of this $\mathrm{KH}$ billow was probably ceased due to the absence of strong wind shears. As a consequence, this $\mathrm{KH}$ billow is believed to get nearly 'frozen-in' the background wind and advected to Gadanki. In absence of the Na lidar measurements, the formation of KH billow over Thiruvananthapuram cannot be unambiguously established. Nevertheless, the wind observations over Thiruvananthapuram and the $\mathrm{Na}$ lidar observations over Gadanki provide credence to the proposition made in the present study. However, it remains to be confirmed whether favorable background conditions in the MLT region can help to sustain the KH billows for a few hours without significant decay. This communication poses an open question on the lifetime of $\mathrm{KH}$ billows in the MLT region. Further investigations including theoretical work along with systematic and coordinated measurements using cluster of instruments possibly can answer this.

\section{Conclusions}

This investigation suggests the physical mechanism behind an unusual structure (resembling a mirror image of $\lambda$ or ' $\lambda_{\text {image }}$ ') observed in the Na layer for around $30 \mathrm{~min}$ in the altitude range of 92 to $98 \mathrm{~km}$ over Gadanki. The meteor wind observation from Thiruvananthapuram and the TIMED satellite measurements of mesospheric temperature over nearby locations reveal the possibility of occurrence of $\mathrm{KH}$ billow in the southwestern part of Indian subcontinent. The horizontal wind direction and magnitude over Thiruvananthapuram indicate that the shape of the $\mathrm{KH}$ billow was modified initially. Later, it got 'frozen-in' the background medium and advected with the northeastward wind to the lidar location where it appeared as the $\lambda_{\text {image }}$ structure in the lidargram. This case study presents a scenario wherein the 'frozen-in' deformed $\mathrm{KH}$-billow structure sustained for a few hours without significant decay in the mesosphere. It is, therefore, suggested that the lifetime of the KH billows in the mesosphere can be of the order of a few hours under favorable background conditions.

\section{Competing interests}

The authors declare that they have no competing interests.

\section{Authors' contributions}

SS carried out Na lidar observation, conceived the ideas, carried out analyses of the work, and prepared the manuscript. JDM, SR, RS, DC, AG, GJ, JHK, RBK, and QW helped in summarizing the theme and manuscript preparation. GR participated in the meteor radar observation. SS participated in Na lidar observation. MGM and JMR supplied SABER data set. All authors read and approved the final manuscript.

\section{Acknowledgements}

J. D. Mathews' and part of S. Sarkhel's component of this effort was supported under the National Science Foundation (NSF) grant ATM 07-21613 and AGS 1241407 to The Pennsylvania State University, USA. The Arecibo Observatory is operated by SRI International under a cooperative agreement with the NSF (AST-1100968), and in alliance with Ana G. Méndez-Universidad Metropolitana, and the Universities Space Research Association. A. Guharay acknowledges support of the Fundação de Amparo à Pesquisa do Estado de São Paulo, Brazil to this present research work. G. Jee, J. Kim, and part of S. Sarkhel's effort is supported by grant PE15010 in the Korea Polar Research Institute, South Korea. NCAR is supported by the NSF. The SKiYMET radar installed at the Space Physics Laboratory was sanctioned under the 10th 5-year plan of the Department of Space, Government of India. The authors thank the director and the supporting staff members of the National Atmospheric Research Laboratory, Gadanki, India for their cooperation in making the observational campaign successful. S. Sarkhel thanks V. Lakshmi Narayanan and S. Gurubaran for useful discussion. This work is also partially supported by the Department of Space, Government of India.

\section{Author details}

${ }^{1}$ Radar Space Sciences Laboratory, 323 Electrical Engineering East, The Pennsylvania State University, University Park, PA, USA. ${ }^{2}$ Space and Atmospheric Sciences, Arecibo Observatory, Center for Geospace Studies, SRI International, Arecibo, Puerto Rico, USA. ${ }^{3}$ Division of Climate Change, Korea Polar Research Institute, Incheon 406-840, South Korea. ${ }^{4}$ Department of Physics, Indian Institute of Technology Roorkee, Roorkee 247667Uttarakhand, India. ${ }^{5}$ Space and Atmospheric Sciences Division, Physical Research Laboratory, Ahmedabad, India. ${ }^{6}$ National Institute for Space Research, São José dos Campos, São Paulo, Brazil. ${ }^{7}$ Space Physics Laboratory, Vikram Sarabhai Space Centre, Thiruvananthapuram, India. ${ }^{8}$ National Atmospheric Research Laboratory, Gadanki, India. ${ }^{9}$ High Altitude Observatory, National Center for Atmospheric Research, Boulder, CO, USA. ${ }^{10}$ Atmospheric Sciences Division, NASA Langley Research Center, Mail Stop 401B, Hampton, VA, USA. ${ }^{11}$ Center for Atmospheric Sciences, Hampton University, 23 Tyler Street, Hampton, VA, USA.

Received: 30 May 2014 Accepted: 10 January 2015

Published online: 11 February 2015

\section{References}

Bhavani Kumar Y, Vishnu Prasanth P, Narayana Rao D, Sundara Murthy M, Krishnaiah M (2007a) The first lidar observations of the nighttime sodium layer at low latitudes Gadanki $\left(13.5^{\circ} \mathrm{N}, 79.2^{\circ} \mathrm{E}\right)$. India Earth Planets Space 59(6):601-611

Bhavani Kumar Y, Narayana Rao D, Sundara Murthy M, Krishnaiah M (2007b) Lidar system for mesospheric Na measurements. J Opt Engg 46:8, doi:10.1117/1.2767271

Bowman MR, Gibson AJ, Sandford MCW (1969) Atmospheric sodium measured by a tuned laser radar. Nature 221:456-457 
Chu X, Yu Z, Gardner CS, Chen C, Fong W (2011) Lidar observations of neutral Fe layers and fast gravity waves in the thermosphere $(110-155 \mathrm{~km})$ at McMurdo $\left(77.8^{\circ} \mathrm{S}\right.$, 166.7E), Antarctica, Geophys. Res Lett 38:L23807, doi:10.1029/2011GL050016

Clemesha BR (2004) A review of recent MLT studies at low latitudes. Ann Geophys 22:3261-3275, doi:10.5194/angeo-22-3261-2004

Clemesha BR, Kirchhoff WWJH, Simonich DM, Takahashi H (1978) Evidence of an extraterrestrial source for the mesospheric sodium layer. Geophys Res Lett 5:873-876

Clemesha BR, Kirchhoff WWJH, Simonich DM, Takahashi H, Batista PP (1979) Simultaneous observations of sodium density and the $\mathrm{NaD}, \mathrm{OH}(8,3)$, and $\mathrm{Ol}$ 5577-Å nightglow emissions. J Geophys Res 84:6477-6482

Clemesha BR, Batista PP, Simonich DM, Batista IS (2004) Sporadic structures in the atmospheric sodium layer. J Geophys Res 109:D11306, doi:10.1029/ 2003JD004496

Collins SC, John MC, Plane MC, Kelley TG, Wright PS, Kane TJ, Gerrard AJ, Grime BW, Rollason RJ, Friedman JS, Gonzalez SA, Zhou Q, Sulzer MP, Tepley CA (2002) A study of the role of ion-molecule chemistry in the formation of sporadic sodium layers. J Atmos Terr Phys 64:845860, doi:10.1016/S1364-6826 (02) 00129-3

Daire SE, John MC, Plane SD, Gamblin PS, Lee EPF, Wright TG (2002) A theoretical study of the ligand-exchange reactions of $\mathrm{Na}+\mathrm{X}$ complexes $(X=\mathrm{O}, \mathrm{O} 2, \mathrm{~N} 2$, $\mathrm{CO} 2$ and $\mathrm{H} 2 \mathrm{O}$ ): implications for the upper atmosphere. J Atmos Terr Phys 64:863870, doi:10.1016/S1364-6826 (02) 00130-X

Deepa V, Ramkumar G, Antonita TM, Kumar KK, Sasi MN (2006) Vertical propagation characteristics and seasonal variability of tidal wind oscillations in the MLT region over Trivandrum $\left(8.5^{\circ} \mathrm{N}, 77^{\circ} \mathrm{E}\right)$ : first results from SKiYMET meteor radar. Ann Geophys 24:2877-2889, doi:10.5194/angeo-24-2877-2006

Dou X-K, Xue X-H, Chen T-D, Wan W-X, Cheng X-W, Li T, Chen C, Qiu S, Chen Z-Y (2009) A statistical study of sporadic sodium layer observed by Sodium lidar at Hefei (31.8 N , 117.3 E). Ann Geophys 27:2247-2257, doi:10.5194/angeo-27-2247-2009

Fan ZY, Plane JMC, Gumbel J (2007) On the global distribution of sporadic sodium layers. Geophys Res Lett 34:L15808, doi:10.1029/2007GL030542

Friedman JS, Chu X (2007) Nocturnal temperature structure in the mesopause region over the Arecibo Observatory $\left(18.35^{\circ} \mathrm{N}, 66.75^{\circ} \mathrm{W}\right)$ : seasonal variations. J Geophys Res 112:D14107, doi:10.1029/2006JD008220

Friedman JS, Tepley CA, Raizada S, Zhou QH, Hedin J, Delgado R (2003) Potassium Doppler-resonance lidar for the study of the mesosphere and lower thermosphere at the Arecibo Observatory. J Atmos Sol Terr Phys 65:1411-1424, doi:10.1016/j.jastp.2003.09.004

Friedman JS, Chu X, Brum CGM, Lu X (2013) Observation of a thermospheric descending layer of neutral Kover Arecibo. J Atmos Sol Terr Phys 104:253-259, doi:10.1016/.j.jastp.2013.03.002

Fritts DC, Palmer TL, Andreassen Ø, Lie I (1996) Evolution and breakdown of Kelvin-Helmholtz billows in stratified compressible flows. Part I: comparison of two- and three-dimensional flows. J Atmos Sci 53:3173-3191

Gao B, Mathews JD (2014a) High-altitude meteors and meteoroid fragmentation observed at Jicamarca. Mon Not R Astron Soc 446(4):3404-3415, doi:10.1093/ mnras/stu2176

Gao B, Mathews JD (2014b) Phase and pattern calibration of the Jicamarca radar using satellites. Mon Not R Astron Soc 446(4):3416-3426, doi:10.1093/mnras/stu2177

Hecht JH, Liu AZ, Walterscheid RL, Rudy RJ (2005) Maui mesosphere and lower thermosphere (Maui MALT) observations of the evolution of Kelvin-Helmholtz billows formed near 86 km altitude. J Geophys Res 110:D09S10, doi:10.1029/ 2003JD003908

Hocking WK (2005) A new approach to momentum flux determinations using SKiYMEI meteor radars. Ann Geophys 23:2433-2439, doi:10.5194/angeo-23-2433-2005

Hocking WK, Fuller B, Vandepeer B (2001) Real-time determination of meteor-related parameters utilizing modern digital technology. J Atmos Sol Terr Phys 63:155-169, doi:10.1016/S1364-6826 (00) 00138-3

Höffner J, Friedman JS (2004) Metal layers at high altitudes: a possible connection to meteoroids. Atmos Chem Phys Discuss 4:399-417, doi:10.5194/acpd-4-399-2004

Hughes DW (1992) The meteorite flux. Space Sci Rev 61:275

Hysell DL, Larsen MF, Zhou QH (2004) Common volume coherent and incoherent scatter radar observations of mid-latitude sporadic E-layers and QP echoes. Ann Geophys 22:3277-3290, doi:1432-0576/ag/2004-22-3277

Kane TJ, Gardner CS (1993) Lidar observations of the meteoric deposition of mesospheric metals. Science 259:12971300, doi:10.1126/science.259.5099.1297

Kane TJ, Hostetler CA, Gardner CS (1991) Horizontal and vertical structure of the major sporadic sodium layer events observed during ALOHA-90. Geophys Res Lett 18:1365-1368
Kane T, Grime B, Franke S, Kudeki E, Urbina J, Kelley M, Collins S (2001) Joint observations of sodium enhancements and field aligned ionospheric irregularities. Geophys Res Lett 28:1375-1378

Kishore Kumar G, Venkat Ratnam M, Patra AK, Vijaya Bhaskara Rao S, Russell J (2008) Mean thermal structure of the low-latitude middle atmosphere studied using Gadanki Rayleigh lidar, Rocket, and SABER/TIMED observations. J Geophys Res 113:D23106, doi:10.1029/2008JD010511

Mathews JD (1996) The dynamics of ion layer generation in the 80-150 km altitude region. J Atmos Terr Phys 58:673-682, doi:10.1016/0021-9169 (95) 00066-6

Mathews JD (1998) Sporadic E: current views and recent progress. J Atmos Solar-Terr Phys 60(4):413-435, doi:10.1016/S1364-6826 (97) 00043-6

Mathews JD, Janches D, Meisel DD, Zhou Q-H (2001a) The micrometeor mass flux into the upper atmosphere: Arecibo results and a comparison with prior estimates. Geophys Res Lett 28:1929-1932, doi:10.1029/2000GL012621

Mathews JD, Machuga DW, Zhou Q-H (2001b) Evidence for electrodynamic linkages between spread-F, ion rain, the intermediate layer, and sporadic-E: results from observations and simulations. J Atmos Solar-Terr Phys 63:1529-1543. doi:10.1016/S1364-6826 (01) 00034-7.

Mathews JD, Briczinski SJ, Malhotra A, Cross J (2010) Extensive meteoroid fragmentation in V/UHF radar meteor observations at Arecibo Observatory. Geophys Res Lett 37:L04103, doi:10.1029/2009GL041967

Mertens CJ, Mlynczak MG, Lpez-Puertas M, Wintersteiner PP, Picard RH, Winick JR, Gordley LL, Russell JM III (2001) Retrieval of mesospheric and lower thermospheric kinetic temperature from measurements of $\mathrm{CO} 215 \mathrm{~m}$ earth limb emission under non-LTE conditions. Geophys Res Lett 28(7):1391-1394

Palmer TL, Fritts DC, Andreassen $\varnothing ~(1996)$ Evolution and breakdown of Kelvin-Helmholtz billows in stratified compressible flows. Part II: instability structure, evolution, and energetics. J Atmos Sci 53:3192-3212

Pfrommer T, Hickson P, She C-Y (2009) A large-aperture sodium fluorescence lidar with very high resolution for mesopause dynamics and adaptive optics studies. Geophys Res Lett 36:L15831, doi:10.1029/2009GL038802

Plane JMC (2003) Mesosphere/metal layers. Encycl Atmos Sci 3:1265-1271

Plane JMC (2004) A time resolved model of the mesospheric Na layer: constraints on the meteor input function. Atmos Chem Phys 4:627-638

Plane JMC, Saiz-Lopez A, Allan BJ, Ashworth SH, Jenniskens P (2007) Variability of the mesospheric nightglow during the 2002 Leonid storms. Adv Space Res 39:562-566

Raizada S, Tepley CA, Aponte N, Cabassa E (2011) Characteristics of neutral calcium and $\mathrm{Ca}^{+}$near the mesopause, and their relationship with sporadic ion/electron layers at Arecibo. Geophys Res Lett 38:L09103, doi:10.1029/ 2011GL047327

Raizada S, Tepley CA, Williams BP, Garcia R (2012) Summer to winter variability in mesospheric calcium ion distribution and its dependence on Sporadic $E$ at Arecibo. J Geophys Res 117:a02303, doi:10.1029/2011ja016953

Richardson LF (1920) The supply of energy from and to atmospheric eddies. Proc R Soc London A 97:354-373

Sarkhel S, Sekar R, Chakrabarty D, Narayanan R, Sridharan S (2009) Simultaneous Na airglow and lidar measurements over India: a case study. J Geophys Res 114:A10317, doi:10.1029/2009JA014379

Sarkhel S, Sekar R, Chakrabarty D, Sridharan S (2010) A case study on the possible altitude-dependent effects of collisions on sodium airglow emission. J Geophys Res 115:A10306, doi:10.1029/2010JA015251

Sarkhel S, Raizada S, Mathews JD, Smith S, Tepley CA, Rivera FJ, Gonzalez SA (2012a) Identification of large-scale billow-like structure in the neutral sodium layer over Arecibo. J Geophys Res 117:A10301, doi:10.1029/2012JA017891

Sarkhel S, Sekar R, Chakrabarty D, Guharay A (2012b) Investigation on mesospheric gravity waves over Indian low latitude stations using sodium airglow observations and a few case studies based on thermal and wind structures. J Atmos Sol Terr Phys 86:41-50, doi:10.1016/j.jastp.2012.06.008

Slipher VM (1929) Emission in the spectrum of the light of the night sky. Publ Astron Soc Pac 41:262-263

Sridharan S, Vishnu Prasanth P, Bhavani Kumar Y, Geetha R, Sathishkumar S, Raghunath K (2009) Observations of peculiar sporadic sodium structures and their relation with wind variations. J Atmos Sol Terr Phys 71:575-582, doi:10.1016/j.jastp.2008.12.002

Taylor MJ, Gu YY, Tao X, Gardner CS, Bishop MB (1995) An investigation of intrinsic gravity wave signatures using coordinated lidar and nightglow image measurements. Geophys Res Lett 22(20):2853-2856

von Zahn U, Gerding M, Hoener J, McNeil W-J, Murad E (1999) Iron, calcium, and potassium atom densities in the trails of Leonids and other meteors: strong evidence for deferential ablation. Meteorite Planet Sci 34:1017-1027 
Walterscheid RL, Hecht JH, Djuth FT, Tepley CA (2000) Evidence of reflection of a long-period gravity wave in observations of the nightglow over Arecibo on May 8-9, 1989. J Geophys Res 105(D5):6927-6934, doi:10.1029/1999JD901065

Xu J, Smith AK (2003) Perturbations of the sodium layer: controlled by chemistry or dynamics? Geophys Res Lett 30(20):2056, doi:10.1029/2003GL018040

Xue XH, Dou XK, Lei J, Chen JS, Ding ZH, Li T, Gao Q, Tang WW, Cheng XW, Wei K (2013) Lower thermospheric enhanced sodium layers observed at low latitude and possible formation: case studies. J Geophys Res Space Physics 118:2409-2418, doi:10.1002/jgra.50200

Submit your manuscript to a SpringerOpen ${ }^{\odot}$ journal and benefit from:

- Convenient online submission

- Rigorous peer review

- Immediate publication on acceptance

- Open access: articles freely available online

- High visibility within the field

- Retaining the copyright to your article

Submit your next manuscript at $\gg$ springeropen.com 